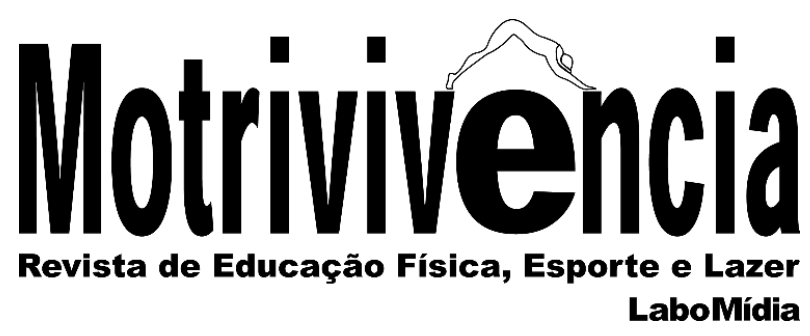

\title{
Das esteiras para as ruas: fatores que levam os alunos de academias às corridas de rua
}

\section{RESUMO}

O estudo buscou conhecer e discutir os fatores que levam um grupo de alunos de academias no Rio de Janeiro que praticam esteira para a prática das corridas de rua. Para atingi-lo, foram entrevistados 10 corredores do sexo masculino e 10 do feminino. $\mathrm{O}$ tratamento das entrevistas se deu por meio da técnica de análise de conteúdo. Os resultados desvelaram a composição de grupos, o discurso da saúde, a presença da competição e a cultura do consumo como os fatores que levam os alunos de academias às práticas de corridas de rua. Portanto, o estudo concluiu que a substituição das esteiras pelas ruas constitui uma decisão multifatorial.

PALAVRAS-CHAVE: Ciências do esporte; Atividade física; Saúde

\section{Jorge Pereira Rodrigues}

Mestre em Ciências do Exercício e do Esporte Universidade do Estado do Rio de Janeiro - UERJ Programa de Pós-Graduação em Ciências do Exercício e do Esporte Rio de Janeiro, Rio de Janeiro, Brasil joprodrigues@globo.com (D) https://orcid.org/0000-0003-1408-5191

Felipe da Silva Triani

Mestre em Humanidades, Culturas e Artes Universidade do Estado do Rio de Janeiro - UERJ Programa de Pós-Graduação em Ciências do Exercício e do Esporte Rio de Janeiro, Rio de Janeiro, Brasil felipetriani@gmail.com

Dhttps://orcid.org/0000-0001-6470-8823

André Malina

Doutor em Educação Física Universidade Federal do Rio de Janeiro - UFRJ Escola de Educação Física e Desportos Rio de Janeiro, Rio de Janeiro, Brasil andremalina@yahoo.com.br

[D https://orcid.org/0000-0001-5832-812X

\section{Silvio de Cassio Costa Telles}

Doutor em Educação Física

Universidade do Estado do Rio de Janeiro - UERJ Programa de Pós-Graduação em Ciências do Exercício e do Esporte

Rio de Janeiro, Rio de Janeiro, Brasil silviotelles@terra.com.br (그ttps://orcid.org/0000-0003-2652-6118 
From the treadmills to the streets: factors that take students from the gym to the street races

\begin{abstract}
The study sought to know and discuss the factors that lead a group of students of academies in Rio de Janeiro practicing treadmill for the practice of street races. To reach it, 10 male and 10 female runners were interviewed. The interviews were handled through the content analysis technique. The results revealed the composition of groups, the health discourse, the presence of competition and the culture of consumption as the factors that lead the students of academies to the practices of street races. Therefore, the study concluded that replacing mats on the streets is a multifactorial decision.
\end{abstract}

KEYWORDS: Sports science; Physical activity; Health

\title{
De las esteras para las calles: factores que llevan a los alumnos de gimnasios a las carreras callejeras
}

\section{RESUMEN}

El estudio buscó conocer y discutir los factores que llevan a un grupo de alumnos de gimnasios en Rio de Janeiro que practican estela para la práctica de las carreras callejeras. Para llegar, se entrevistó a 10 hombres y 10 mujeres. Las entrevistas se manejaron a través de la técnica de análisis de contenido. Los resultados revelaron la composición de los grupos, el discurso de la salud, la presencia de la competencia y la cultura del consumo como los factores que llevan a los estudiantes de las academias a las prácticas de las carreras callejeras. Por lo tanto, el estudio concluyó que reemplazar esteras en las calles es una decisión multifactorial.

PALABRAS-CLAVE: Ciencia del deporte; Actividad física; Salud 


\section{INTRODUÇÃO}

O fenômeno das corridas de rua com milhares de indivíduos correndo pelas avenidas das grandes cidades demonstra que os espaços fechados das academias não bastam para suprir as necessidades de atividade física da sociedade moderna. Um estudo anterior (TRUCCOLO; MADURO; FEIJÓ, 2008) encontrou associação entre aspectos sociais e adesão aos eventos de corridas de rua. Para essa associação, aplicaram um questionário a 68 corredores durante uma competição em Porto Alegre, no Rio Grande do Sul e, como resultado, as razões psicológicas como aumento da autoestima, melhora da imagem corporal, diminuição da ansiedade e redução do estresse, e também as razões sociais como a formação de grupos foram identificadas como uma das mais importantes para a adesão de adultos em um programa de exercício físico e estão diretamente relacionadas com apoio social.

O sistema capitalista se apropria desse momento fazendo uma atividade de lazer reverberar as características básicas do esporte moderno que podem ser sumariamente resumidas em competição, rendimento físico e técnico, recordes, racionalização e cientifização do treinamento. Anteriormente, já foi apontado (DIAS; ALVES JÚNIOR, 2007) como a contemporaneidade tem criado uma nova cultura da prática esportiva não profissional. Para os autores há uma institucionalização das atividades físicas vinculadas ao lazer.

A Indústria do Fitness está sempre em busca de novidades nos serviços que renovem seu poder de atração de novos e potenciais consumidores. As promessas dessa grande indústria, contando com um avançado aparato no campo do marketing e da propaganda, criam novas necessidades junto com o campo científico, ambos legitimando o discurso da saúde, promovendo uma identificação do consumidor com produtos e serviços propostos pelo setor. $\mathrm{O}$ evento de corridas denominado "Corrida das Academias" é um bom exemplo de empreendimento que ratifica essa busca por ampliação de mercado.

Permanecer nas esteiras não está sendo mais suficiente para um número cada vez maior de pessoas. Deixar esse ambiente controlado, com ar condicionado, com reduzido risco de acidentes, monitores de TV e vestiários ao rápido alcance tem se tornado uma constante para quem gosta de correr. Assim, o objetivo desta investigação foi conhecer e discutir os fatores que levam um grupo de alunos de academias no Rio de Janeiro que praticam esteira para a prática das corridas de rua.

\footnotetext{
${ }^{1}$ Trata-se de um evento de corrida de rua organizado por algumas academias com o objetivo de divulgar sua marca. Nela, grande parte dos corredores são alunos das próprias academias. O evento é organizado por uma empresa e permite a participação de corredores individuais, porém possui uma metodologia de inscrição, participação e premiação para grupos vinculados a academias.
} 
Nessa perspectiva, pressupondo que os fatores que implicam a substituição das esteiras pelas ruas sejam comportamentais, os estudos (WEINBERG; GOULD, 2001; SMIT, 2007; MASSARELLA; WINTERSTEIN, 2009; ALMEIDA; GUTIERREZ; MARQUES, 2012) da psicologia do esporte compuseram a base teórica utilizada para a discussão dos resultados, sendo as categorias analisadas por esse viés.

\section{MÉTODOS}

A população do estudo foi composta por alunos de academias participantes de corridas de rua. A amostra foi composta por 20 adultos pertencentes a equipes de corrida de rua, sendo 10 homens e 10 mulheres. Os critérios de inclusão da amostra foram: i) idade entre 20 e 60 anos. A opção pela faixa etária se deu pelo fato de que é nesse lapso etário que se concentra a maior parte dos inscritos nas corridas de rua; ii) que fossem praticantes de corrida de rua há pelo menos 6 meses e possuísse vinculo de matrícula com a academia. Cabe ressaltar que todos participaram de maneira voluntária por meio da assinatura do termo de consentimento livre e esclarecido e que o projeto foi aprovado pelo comitê de ética em pesquisa sob guarda do número: 76695517.0.0000.5259.

Como fator de exclusão estabeleceu-se que não entrevistaríamos pessoas que tivessem vínculo contratual na categoria de atleta/corredor que caracterizasse o informante como profissional, conforme disposto na lei $9.615 / 98$ em seu artigo 28 e seus parágrafos, caracterizado por recebimento de proventos e contrato formal de trabalho para representar a academia.

Para obtenção dos dados foi realizada uma entrevista semiestruturada do tipo guiada pautada em um roteiro. Segundo Severino (2007), ao elaboramos um roteiro para entrevistas, buscamos as mesmas ou semelhantes informações dos entrevistados. Essa ferramenta permitiu o ajuste da sequência e o vocabulário das questões em função do entrevistado.

A análise de conteúdo (BARDIN, 2016) foi utilizada como instrumento de tratamento de dados, sendo assim, após transcrição das entrevistas, foi realizada uma leitura flutuante, objetivando identificar dimensões para a criação das categorias, unidades de contexto e registros. Esse processo resultou na criação de quatro categorias de análise, conforme ilustrado na Tabela 1. 
Tabela 1 - Categorias de análise, unidade de contexto e unidade de registro resultante dos dados da pesquisa Abreviaturas de alguns meses

\begin{tabular}{ccc}
\hline Categoria & $\begin{array}{c}\text { Unidade de } \\
\text { contexto }\end{array}$ & Unidade de registro \\
\hline \multirow{2}{*}{ Grupo } & Amizade & Incentivo \\
& Família & \\
& Atividade social & Rito, família, relacionamentos (familiares \\
& & afetivos) \\
\hline \multirow{2}{*}{ Saúde } & Estética & Emagrecimento \\
& Condicionamento & Melhorar o tempo \\
\hline \multirow{2}{*}{ Competiçã } & Superação & Desempenho \\
o & Desafio & Kit, água, relógios \\
\hline Consumo & Estrutura & Maratona \\
\hline
\end{tabular}

Fonte: os autores.

\section{RESULTADOS E DISCUSSÃO}

\section{Grupo}

$\mathrm{Na}$ entrevista ao questionarmos sobre as práticas da academia e as corridas de rua, pode-se perceber uma expressiva presença do grupo como fator decisivo para as práticas de corrida de rua. Durante as entrevistas, foi comum expressões como "a galera da academia", "o pessoal da academia" ou "o grupo da academia".

Diversos estudos também coadunam com o potencial que tem o grupo. Um deles (ZIMERMAN; OSÓRIO, 2002) assinala que grupo não é apenas um somatório de pessoas, mais algo que se transforma em uma entidade com normas tácitas que tendem a manter sua coesão. Em outro (ROBBINS, 2002) são apontadas questões como segurança, status, autoestima e associação, como motivos que contribuem para que pessoas busquem grupos como parte de seus convívios, de modo a facilitar o alcance de metas.

Moretti (2009) pontua que a coesão grupal possui três sentidos, sendo o primeiro a atração do grupo que diminui a possibilidade de afastamento entre seus participantes, o segundo a motivação dos membros em participar de atividades em comum e ainda a coordenação de esforços para o alcance dos objetivos propostos coletivamente. 
Em se tratando do potencial do grupo, cabe destacar que algumas corridas de rua utilizam desse conhecimento. Dessa maneira, eventos incentivam esse tipo de participação, como corridas de rua de revezamento, as quais o êxito está no somatório de tempo alcançado por todos os membros do grupo e as premiações se destinam às equipes com maior número de participantes. Além dessas, há também as corridas das academias, que embora não vetem a participação de corredores individuais, as ações são direcionadas para a competição entre grupos.

Em se tratando de grupo, Rubio (2003) o define sobre aspectos primários e secundários. O primeiro é composto pelas relações parentais nas quais se tem a presença de familiares e cônjuges e o segundo faz referência a todos que não se enquadram no primeiro caso. Nesse sentido, ao analisar as entrevistas, foi observado o quanto o grupo, os familiares e as amizades decorrentes da convivência grupal atuam como vetor na adesão e aderência às práticas de corridas pelos praticantes.

Dessa maneira, na ocasião das entrevistas foi questionado se os familiares também participavam dos eventos e 12 entrevistados disseram que não. Os demais responderam que havia participação, sendo a maioria nas caminhadas ou corridas curtas do tipo "Family Run", que são eventos menores embutidos nas corridas principais.

$\mathrm{Na}$ ocasião das entrevistas foi observado que quando os entrevistados se reportavam a participação de algum membro familiar nas corridas, em todos os casos, havia um semblante que fazia referência a uma postura de aprovação, felicidade e vontade de ser explicativo, conforme as seguintes narrativas:

Minha irmã acabou de correr com o meu nome porque eu estou de licença médica. Ela acabou de correr a primeira corrida e eu estou bem feliz de tá trazendo também a minha família pra isso (entrevistado 4).

Participa. Até ia trazer minha mãe e meu pai, mas aqui comigo está minha sogra e meu sogro. Meu noivo está em casa, hoje não deu pra ele vir, mas sempre estão presente (entrevistado 13).

Minha mãe participa das caminhadas há pouco tempo. De um mês pra cá comecei inscrevê-la, agora o meu filho começou (entrevistado 14).

Minha mulher e minha sogra fazem a Family Run. Já botei meu filho para a corrida kids (entrevistado 19).

No percurso das entrevistas, foi questionado o maior incentivo que contribuiu na condução do início da atividade de corrida, sendo assim, somente 5 dos entrevistados disseram que decidiram correr por iniciativa própria, já os demais aderiram à prática da corrida por intervenção familiar ou de amigos. Nesse sentido, dentre os motivos extrínsecos que incentivaram as pessoas a correrem, em 
alguns casos, referenciou-se o professor de educação física da academia que contribuiu de forma motivacional e técnica.

Essa motivação externa, de acordo com os entrevistados, surge dos grupos de alunos da academia. Nessa perspectiva, Massarella e Winterstein (2009) ao estudar a motivação intrínseca para a prática de corridas de rua, identificaram a convivência ou inserção grupal como elementos mais presentes entre os corredores. Dessa maneira, de acordo com Massarella e Winterstein (2009), é possível perceber que embora, nas palavras dos corredores, a motivação seja externa, é a motivação intrínseca que explica o interesse de pessoas que se mantêm motivadas em realizar atividades e reperti-las, explicando o seu comportamento de gastar muito tempo em determinadas atividades sem uma recompensa externa evidente, isto é, as recompensas pela realização das atividades são inerentes aos sentimentos positivos vivenciados.

Nessa perspectiva, quando a tarefa é realizada a partir de recompensas extensas e essas são atingidas, de acordo com Massarella e Winterstein (2009), a motivação extrínseca tende a se deteriorar, mas se a realização da atividade se mantém constante é a motivação intrínseca que explica a sua permanência na tarefa.

Ao questionarmos se os entrevistados percebiam o incentivo do grupo à sua prática de corridas, foi encontrada uma convergência quase absoluta, conforme as seguintes narrativas:

Quando dá preguiça para treinar ou competir eles sempre dão uma força (entrevistado 1).

O grupo é legal. Na academia a gente treina sozinho. Na rua é legal correr com os parceiros (entrevistado 4).

Ah! É sempre legal correr com os amigos. Quando bate o cansaço um ajuda o outro (entrevistado 5).

Eu comecei por conta própria, mas depois a galera vira uma espécie de família (entrevistado 6).

Faz a gente se sentir culpada quando está com preguiça de correr (entrevistado 11).

Pra mim foi tudo. Comecei a correr por conta deles. Embora eu goste de correr, acho que se eles pararem eu perco um pouco do estímulo. Um dá força para o outro (entrevistado 16).

Esse grupo é massa. Um dá força para o outro. Quem chega por último tem pagar uma rodada de chopp pra galera. Tem também o batismo. Na primeira corrida de alguém, ele leva um banho de chopp (entrevistado 17).

Após as entrevistas, pode-se perceber que o grupo é um elemento com potencial influência na tomada de decisão de sair da esteira e ir praticar a corrida de rua. O convívio, a proximidade de 
objetivos e o incentivo externo, apresentaram-se como consideráveis fatores motivadores para a prática da corrida de rua, se destacando o apoio de familiares e amigos que, com efeito, tende a fortalecer a sensação de bem-estar e realização no indivíduo. No entanto, embora o grupo se apresente como notável influência externa, a permanência na prática da corrida de rua se explica pela motivação intrínseca do corredor, pois a motivação extrínseca deixa de existir na medida em que o alvo é atingido (MASSARELLA; WINTERSTEIN, 2009).

\section{Saúde}

Durante o roteiro de entrevista sete corredores assinalaram a qualidade de vida como um dos fatores determinantes na adoção da corrida de rua como prática. Três indicaram a questão da estética corporal e os demais atribuíram à adoção da prática ao condicionamento físico. Nessa perspectiva, corroborando com esses resultados, Santos e Knijnik (2006) identificam o condicionamento físico, devido a sua capacidade de desenvolver aumento da autoestima corporal e autônima, como elemento associado à qualidade de vida.

Em se tratando de qualidade de vida, Nahas (2010, p.14) a define como percepção de bemestar "resultante de um conjunto de parâmetros individuais e socioambientais modificáveis ou não, que caracterizam condições em que vive o ser humano". Para o parâmetro socioambiental, são atribuídas questões ligadas à moradia, transportes e condições de trabalho. Já no parâmetro individual, a escolha do estilo de vida predomina. Isso ajuda a explicar o motivo pelo qual pessoas associarem a prática regular de atividade física à qualidade de vida.

A noção de que saúde e qualidade de vida melhoram diretamente a partir da adoção de estilos de vida saudáveis, trata-se de uma estratégia de controle social (GONÇALVES; VILARTA, 2004). Almeida, Gutierrez e Marques (2012), apontam os efeitos coercitivos que os meios de comunicação causam à qualidade de vida como uma espécie de obrigação do cidadão. Essa lógica reforça o discurso de culpabilização (PALMA, 2001) dos sujeitos que não praticam exercício físico, isto é, não se analisa qualitativamente se esses sujeitos possuem condições para essa prática, uma vez que muitos se encontram em condição de vulnerabilidade social.

Essa análise não tem por objetivo negar os possíveis benefícios pessoais na decisão das pessoas incluírem as corridas como prática. Apenas ressalta-se que algumas das respostas obtidas junto aos entrevistados podem estar contaminadas a partir dos discursos hegemônicos ou simplesmente atreladas ao senso comum, isto é, causa e efeito, como diz o jargão "pratico atividade física para ter saúde". Essa atitude muitas vezes desconsidera um rol de circunstancias que envolve 
a real possibilidade de aquisição da tão almejada qualidade de vida.

$\mathrm{Na}$ entrevista, quando questionado sobre os fatores que os entrevistados consideram importantes para a prática de corridas de rua, diversos termos foram ditos. Na maioria, contudo, orbitavam os termos competição, performance, amizade, família, qualidade de vida e saúde.

É importante destacar que, quando a resposta tratava-se dos termos associados à categoria qualidade de vida e saúde, os entrevistados, por vezes, pausavam antes de responder, sugerindo uma espécie de resposta socialmente aceitável. Por outro lado, quando os entrevistados referiam-se ao condicionamento físico e/ou estética, davam respostas acompanhadas de complementos que as referendavam. Esses resultados podem ser observados nas seguintes narrativas:

Condicionamento físico. A gente malha pra poder ficar bem, a gente tem mais acesso a comer as coisas com mais tranquilidade, estético também né? Acho que $\operatorname{sim}$ (entrevistado 1).

Mas é legal pra saúde e ajudar a emagrecer. A idade vai chegando (entrevistado 12).

Acho que eu só queria perder peso mesmo. Claro que isso influencia na saúde da gente (entrevistado 15).

Mas ajudou a perder um pouco da barriguinha, já perdi $4 \mathrm{~kg}$. Sempre rola um chopinho depois pra falar da corrida. Por isso que eu corro, porque aí eu bebo sem culpa (entrevistado 17).

Todas as demais respostas relacionadas à qualidade de vida e saúde foram terminais, não havendo nenhum processo explicativo sobre o motivo da escolha. É possível que haja nessas respostas a influência dos discursos hegemônicos de saúde e qualidade de vida. Nesse sentido, Truccolo, Maduro e Feijó (2008) assinalam que o conhecimento e a crença em benefícios pessoais decorrentes da atividade física são fortes moventes individuais a essas práticas. Além disso, o estudo ainda revela que por conta da facilidade do movimento e a grande oferta de eventos, a corrida de rua apresenta-se como uma forte possibilidade das pessoas alcançarem seus objetivos de aquisição de saúde.

De outro modo, Balbinotti e outros (2015), ao estudaram os perfis motivacionais de 62 corredores de rua para entender os motivos que levam indivíduos à prática. $\mathrm{Na}$ ocasião, identificaram que o controle do estresse, a saúde, a sociabilidade, a competitividade, a estética e o prazer correspondem à dimensões motivadoras para a prática. No entanto, a competitividade se mostrou como uma das dimensões mais expressivas, evidencia que implica interpretar que a presença da competição na prática do esporte pode servir como imã que aproxima o sujeito da corrida. 
Nessa perspectiva, o estudo de Oliveira (2010) analisou um grupo de corredores e buscou investigar se a prática de corrida estava sendo exercida somente na dimensão do lazer ou se estava ultrapassando os limites preconizados para a prática saudável de atividade física. Como resultado, foi observado que muitos praticantes de corrida estavam sofrendo lesões, principalmente pela tentativa de melhorar o rendimento na corrida, algo que, em longo prazo implicou no início de frustrações, principalmente pelo impedimento da melhora do desempenho. A obtenção/manutenção da saúde pode ser conquistada correndo apenas nas esteiras, mas assim como o conceito de saúde não pode se encerrar apenas na ausência de doença e sim em um conglomerado de situações, da mesma forma as múltiplas sensações que as corridas de rua proporcionam são mais decisivas do que uma atividade com fim em si mesma com as esteiras.

Por fim, cabe lembrar que a mídia contribui para um pensamento generalizado de que a prática do exercício físico apresenta-se como uma solução ao alcance da qualidade de vida. Dessa maneira, quando o praticante mergulha nesse ambiente é perceptível uma sensação de desculpabilização (ALMEIDA; GUTIERREZ; MARQUES, 2012).

\section{Competição}

$\mathrm{Na}$ antiguidade, e de forma bem eloquente na Grécia Antiga, a corrida assume o status de competição. Essa característica, de acordo com Oliveira (2010) não deixou de existir. Contudo, a partir da revolução industrial, quando há uma drástica alteração do modus vivendi da população, a corrida conquista uma nova roupagem, o de lazer moderno.

Weinberg e Gould (2001) acrescentam que a solução de tarefas, aquisição de excelência esportiva, superação de obstáculos e demonstração de performance como variáveis competitivas, contribuem como elementos de motivação em atividades esportivas, ocasião em que o praticante amador assume, de maneira ficcional, o status de atleta.

Nas entrevistas foi possível observar indícios de elementos que mantêm a manutenção da corrida de rua como prática regular, como a busca pela performance, melhoria no tempo de prova e superação de limites. Além disso, as competições de corrida potencializam as sensações e anseios dos corredores. Essas afirmações podem ser observáveis em trechos das entrevistas:

Assim, o fato de eu estar sempre melhorando o resultado, está sempre melhor, estou sempre conseguindo melhorar, ou não piorar. Pelo menos manter estável. Daí manter a forma. Enfim, tem varias coisas (entrevistado 5).

Melhorar meu tempo (entrevistado 6). 
Testar meus limites (entrevistado 8).

Acho que o fato de eu tentar me superar cada vez mais. Sempre está me superando, não é superar ninguém, é me superar entendeu? (entrevistado 9).

Competição (entrevistado 18).

Melhorar o resultado é uma característica inerente ao atleta, pois disso depende suas recompensas materiais. No entanto, o que se percebe nas narrativas são associações da prática de corrida de rua, com ênfase nos eventos competitivos, não sendo somente entendida pelos praticantes como prática esportiva de lazer, mas como prática com vistas ao rendimento.

Essa percepção parece contrária ao que se encontra na literatura, pois, relembrando as Dimensões Sociais do Esporte, propostas por Tubino (2006), há de se perceber que existem três manifestações do esporte, são elas: educacional, participação e performance. Na primeira, a prática ocorre por meio dos princípios socioeducativos, a segunda pelo princípio do prazer e a terceira quando o praticante tem a profissão de atleta (ALMEIDA; GUTIERREZ; MARQUES, 2012; TRIANI, 2016). Dessa maneira, embora não seja possível identificar claramente os praticantes de corrida de rua como atletas, praticar a corrida a partir de uma vertente associada à competição, proporciona uma identificação com o "ser atleta".

Ao questionar sobre as formas de preparação para os eventos de corrida de rua e o local onde acontece, os entrevistados afirmaram seguir uma rotina de treinamento, conforme ilustrado na Tabela 2.

Tabela 2 - Perfil de treinamento dos corredores entrevistados

\begin{tabular}{cccc}
\hline Sessões de Treino & n & Local & N \\
\hline Até duas vezes & 5 & & \\
Três vezes & 7 & Academia & 8 \\
Quadros vezes & 2 & & \\
Cinco vezes & 3 & Academia e rua & 12 \\
Mais de cinco vezes & 3 & & \\
\hline Segue rotina de treino & \multicolumn{3}{c}{ Estabelece metas } \\
\hline Sim & 16 & Sim & 10 \\
Não & 4 & Não & 10 \\
\hline \multicolumn{3}{c}{ Fonte: Os autores }
\end{tabular}

Destaca-se que é possível identificar a mídia reforçando o discurso do praticante/atleta por meio de eventos de corrida intitulados "Eu Atleta", muito presente nas propagandas de televisão.

Salgado e Mikahil (2010) reforçam que aderir a prática do exercício físico mergulha o sujeito no discurso da estética, promoção da saúde, integração social, prazer e competição. Nesse sentido, para os autores, ser competitivamente bem classificado tornou-se um atrativo, visto que o elevado 
número de corridas de rua permite constantes mensurações de seus desempenhos. Ter a chance de melhorar sua performance e poder compartilhar junto ao grupo de convívio, permite usufruir não somente do processo de autossatisfação, mas também uma possibilidade de posição elevada na estrutura social do grupo que corre. Isto a esteira também não pode oferecer.

Oliveira (2010) ressalta que os diferentes formatos de corridas oferecidos pelas empresas organizadoras, permite um maior número de pessoas, com diferentes níveis de treinamento em participar dos eventos. Para o autor, a corrida serve para que pessoas com diferentes faixas etárias e de níveis de treinamento interajam e ampliem as perspectivas sociais ao observar o resultado e a visão do outro que pratique o mesmo tipo de atividade, chegando até mesmo a reproduzir um discurso intitulado de "lazer sério".

Na medida em que os sujeitos têm mais oportunidades de participar dos eventos, amplia-se a busca pelo desempenho e provavelmente a presença do grupo exerça algum tipo de pressão, uma vez que o prestígio social por conta do resultado tende a elevar a posição social perante aos outros.

Para Massarella e Winterstein (2009), estabelecer metas e perceber que estejam no caminho de alcançá-las, são fatores que reforçam os processos motivacionais. Dessa maneira, observa-se que muitos dos entrevistados argumentam que possuíam como objetivos a melhora do resultado, superação de limites ou poder competir em distâncias maiores do que aquelas que já competiam.

\section{Consumo}

Nas entrevistas foi visível muitas questões relacionadas ao consumo que não são oportunizadas na prática da corrida em esteiras. Nesse sentido, emergiu a criação da categoria "consumo" como uma possibilidade de desvelar seu efeito nas filiações das pessoas às corridas de rua, pois de acordo com Albuquerque (2007) as empresas cada vez mais se conscientizam que os aspectos relacionados ao consumo, possuem importante influência na mente dos corredores. Dessa maneira, as empresas buscam a criação de um laço com seus consumidores em potencial.

Tranchitella (2014), ao abordar os gerenciamentos de riscos em eventos esportivos de corridas de rua, relata os procedimentos desenvolvidos pelos gestores no sentido de estreitar e fidelizar o seu público alvo. Essas ações podem ser percebidas à medida que os entrevistados afirmam receber informações por parte das academias quanto aos eventos de corrida de rua.

A reprodução de discursos de consumo pode ser observável nas narrativas dos entrevistados, ora positivos, ora negativos frente aos seus anseios para com as empresas que organizam, mas em todos os casos os corredores se colocam na qualidade de consumidor do esporte: 
Tem o Kit que, também, é muito legal (entrevistado 6).

O legal seria blusa, medalha né, é tudo o que eles dão (entrevistado 11).

Essa teve a marcação em todos os $\mathrm{Km}$ foi muito bom para a gente poder acompanhar o tempo e a velocidade e as barracas também que dão apoio aos "atletas" ai com massagem (entrevistado 13).

Eu acho tudo legal, acho legal essa toalhinha (parte do kit), as camisas, viseiras. Eu gosto dessas coisas (entrevistado 16).

Tá bem organizado. Horários, entrega do kit e apoio (entrevistado 17).

Gosto do kit (entrevistado 18).

Eu acho que hoje virou um comércio muito grande e vendem mais e não dão tanta infraestrutura pra gente (entrevistado 1).

Eu acho que tinha que melhorar a infraestrutura de banheiro, de saída é, eu acho que o kit foi muito fraco eram melhores, acho que tinha que melhorar a infraestrutura pelo serviço que paga pelo valor que é (entrevistado 3).

Colocar aqueles chuveirinhos no meio do caminho, porque nessa época do ano o calor é muito grande, a água está sempre quente dificilmente você consegue beber água gelada no meio do caminho então se tivesse esses pontos ao invés de as pessoas ficarem tomando banho com a garrafinha, tivesse aquele chuveirinho aquele isorpozinho no meio do caminho, acho que seria muito melhor. Até iria ter água gelada para todo mundo (entrevistado 10).

Mais banheiros, limpos de preferência (entrevistado 14).

$\mathrm{Eu}$ acho que tem andado muito cheio (entrevistado 19).

Diante dos discursos de consumo parece cabível e oportuno referenciar Lasch (1983), quando relata como a produção capitalista, com a necessidade de manter sua política, transformou os trabalhadores de produtores em consumidores, sendo a mídia decisiva para garantir o consumo em larga escala dos produtos das indústrias. Então, o consumo deixou de ser algo pertencente apenas a um grupo seleto e passou a influenciar o modo de vida de outras camadas da população. Nesse sentido, Smit (2007) reforça assinalando como as indústrias de produtos esportivos lançaram mão da imagem dos ídolos do esporte como forma de alimentar no imaginário social, a ideia de que consumir produtos de ídolos esportivos poderia proporcionar uma sensação de rendimento pessoal e sucesso.

É oportuno ainda lembrar Debord (1997), quando denuncia o quanto a propaganda compele o sujeito a um processo obsessivo de consumo. Cria-se um processo hierárquico no qual os símbolos relacionados à utilização de produtos posiciona o cidadão em organogramas sociais. Em sua obra, o consumo é uma das formas encontradas para o sujeito transformar-se em protagonista no 
“espetáculo social". Ver e ser visto durante a corrida e ainda postar nas redes sociais tornou-se uma prática comum para diversos corredores. Ostentar a medalha, a camisa do evento, o tempo da corrida e a colocação final, se tornaram sinais de prestígio, sucesso e conquista.

Diante desses entendimentos, colocando a corrida de rua como um produto a ser consumido, Ahouagi, Gosling e Andrade (2015) assinalam que o mercado nesse segmento, anualmente apresenta crescimento continuo tanto de eventos como de participantes. Sobre essa evidência, é pertinente destacar que há influências positiva e negativa, a primeira faz referência ao aumento do número de praticantes de corrida e difusão do esporte, já a segunda é concernente ao uso do esporte como mecanismo de difusão da cultura do consumo, isto é, evidenciando um número cada vez maior de marcas esportivas que procuram se associar às empresas organizadoras de eventos rústicos.

Atualmente, "Corrida das Estações MIZUNO", "FILA NigthRun", "Meia Maratona ASICS" e "Circuito NIKE Run" são exemplos de como algumas das marcas de produtos esportivos “emprestam" seus nomes às corridas de rua. Além dessas, há também o crescimento de corridas temáticas como "Corrida dos Namorados", "Corrida da Mulher" e "Corrida das Academias" (TRANCHITELLA, 2014). Nesse sentido, Ahouagi, Gosling e Andrade (2015) descrevem que as organizações têm percebido nas corridas de rua uma oportunidade de reforçar seus valores e de se legitimar perante seus segmentos de mercado.

O produto ou a simbologia que a marca representa tende a desenvolver no praticante de corrida uma sensação de como se estivesse sendo "patrocinado pela marca", reforçando a representação social do "ser atleta". De acordo com Ahouagi, Gosling e Andrade (2015), as marcas apresentam tanto aspectos racionais, que são diretamente vinculados ao desempenho do produto, quanto aos aspectos simbólicos, que se referem àquilo que ela representa.

Percebe-se que nas corridas de rua os corredores são instigados pelo imaginário de sucesso, reproduzindo um momento "atleta", elementos de consumo que não se fazem presentes nas práticas das corridas em esteiras, devido a sua variabilidade comportamental previsível e limitada. No entanto, cabe corroborar com Reis, Telles e DaCosta (2013) ao afirmar que, embora a mídia seja capaz de influenciar de maneira negativa, também há de se perceber sua participação positiva na medida em que promove o fomento e aumenta a prática esportiva junto à população local.

\section{CONCLUSÕES}


A substituição ou aderência e adesão das esteiras pelas corridas de rua por parte de alunos de academias se apresenta como uma questão multifatorial. As entrevistas possibilitaram a criação de quatro categorias que quando articuladas, podem conduzir a compreensão dos fatores que desenvolvem tal mudança de hábito, por meio dos elementos que motivam o grupo entrevistado a extrapolar as possibilidades de exercitação em ambientes indoor e buscar nas corridas de rua suas realizações.

As respostas obtidas revelaram que os discursos pela aquisição de saúde, estética e corpo saudável, influenciam os corredores a se filiar a um processo de obrigatoriedade social. O discurso social contemporâneo impõe a necessidade de estar apto físico e mentalmente para satisfazer o paradigma utilitarista. Além disso, há a sensação de poder estar diretamente relacionada à possibilidade de consumir e através desse consumo filiar-se a um estilo atlético e saudável de ser. Por esse motivo, as corridas de rua parecem ser úteis, na medida em que atendem a duas necessidades impostas, isto é, a prática regular de exercício físico e a cultura do consumo.

As relações grupais atuam como fator de fortalecimento e transformação para os corredores. $\mathrm{O}$ fortalecimento se apresenta na ocasião em que o evento desenvolve um senso de pertencimento gerando/despertando características similares entre os participantes, reforçando o sentimento de poder pessoal e identificando em seus pares perfis que lhe causem admiração. Ver e ser visto e, mais ainda, fazer parte de um movimento que representa saúde e hábitos saudáveis passou a ser um diferencial que as esteiras não oferecem.

A competição emerge como símbolo de performance, seja através da indicação do vencedor ou pela mensuração da melhoria do desempenho pessoal. Atuar em uma prova esportiva representa a possibilidade real de obter um feedback quanto a sua capacidade produtiva. Além disso, cria no imaginário do praticante a representação do "ser atleta".

\section{REFERÊNCIAS}

AHOUAGI, Joana Ferreira; GOSLING, Marlusa Sevilha; ANDRADE, Marcelo Aureliano. Percepções de Marca e Comportamento do Corredor de Rua. Unopar Científica: Ciências Jurídicase Empresariais, Arapongas, v. 16, n. 1, p. 3-13, 2015.

ALBUQUERQUE, Rubens Caetano. Comportamento do Consumidor de Materiais Esportivos para a Prática da Corrida de Rua na Região metropolitana de Belo Horizonte. Dissertação (Mestrado Profissional em Administração), Faculdades Integradas de Pedro Leopoldo. Pedro Leopoldo, MG, 2007. 
ALMEIDA, Marco Antonio; GUTIERREZ, Gustavo Luis; MARQUES, Renato. Qualidade de Vida: definição, conceitos e interfaces com outras áreas de pesquisa. São Paulo: EACH/USP, 2012, $142 p$.

BALBINOTTI, Marcos Alencar et al. Perfis motivacionais de corredores de rua com diferentes tempos de prática. Revista Brasileira de Ciências do Esporte, Brasilia, v. 7, n. 1, p. 65-73, 2015.

BARDIN, Laurene. Análise de conteúdo. Lisboa: Edições 70; 2016, 235p.

DEBORD, Guy. Comentários Sobre a Sociedade do Espetáculo. Editora: Contraponto, Rio de Janeiro; 1997, 544p.

DIAS, Cleber Augusto; MELO, Victor Andrade; ALVES JÚNIOR, Edmundo Drummond. Os estudos dos esportes na natureza: desafios teóricos e conceituais. Revista Portuguesa de Ciências do Desporto, Porto, v. 7, n. 3, p. 358-367, 2007.

GOMES, Ingrid Rodrigues; CHAGAS, Regiane de Avila; MASCARENHAS, Fernando. A indústria do fitness, a mercantilização das práticas corporais e o trabalho do professor de educação física: o caso da body systems. Movimento, Porto Alegre, v. 16, n. 4, p. 169-189, 2010.

GONÇALVES, Aguinaldo; VILARTA, Roberto. Qualidade de vida: identidades e indicadores. In: GONÇALVES, Aguinaldo; VILARTA, Roberto. (Orgs). Qualidade de vida e atividade física: explorando teorias e práticas. Barueri: Manole, 2004, 239p.

LASCH, Christopher. A cultura do narcisismo: a vida americana numa era de esperanças em declínio. Rio de Janeiro: Imago; 1983, 349p.

MASSARELLA, Fábio Luiz; WINTERSTEIN, Pedro José. A Motivação Intrínseca e o Estado Mental Flowem Corredores de Rua. Movimento, Porto Alegre, v. 15, n. 2, p. 45-68, 2009.

MORETTI, Alexandro Roberto. Corridas de Aventura: Processos de Coesão Grupal na Superação de Obstáculos. 2009. Dissertação (Mestrado em Psicologia Social) PUC/São Paulo, 2009.

NAHAS, Markus Vinicius. Atividade física, saúde e qualidade de vida: conceitos e sugestões para um estilode vida ativo. 5. ed. Londrina: Midiograf, 2010, 189p.

OLIVEIRA, Saulo Neves. Lazer Sério e Envelhecimento: Loucos por corrida. Dissertação (Mestrado em Educação) Programa de Pós-Graduação em Educação da Universidade Federal do Rio Grande do Sul. Porto Alegre, 2010.

PALMA, Alexandre. Educação Física, Corpo e Saúde: um reflexão sobre os outros "modos de olhar”. Revista Brasileira de Ciências do Esporte, Brasília, v. 22, n. 2, p. 23-39, 2001.

REIS, Romulo Meira; TELLES, Silvio Cassio Costa; DACOSTA, Lamartine. Estádios da copa de 2014: perspectivas de um legado. Revista Pensar a Prática, Goiânia, v. 16, n. 2, p. 583-599, 2013.

RUBIO, Katia. Estrutura e Dinâmica dos Grupos Esportivos. In: RUBIO, K. (org.). Psicologia do Esporte: Teoria e Prática. São Paulo: Casa do Psicólogo, 2003, 478p. 
ROBBINS, Stephen. Comportamento Organizacional. 9a ed., São Paulo, Prentice Hall: 2002, $278 \mathrm{p}$.

SALGADO, José Victor Vieira; MIKAHIL, Mara Patraicia Traina Chacon. Corrida de rua: análise do crescimento do número de provas e de praticantes. Conexões: Educação Física, Esporte e Saúde, Campinas, v. 4, n. 1, p. 100-110, 2010.

SANTOS, Susan Cotrim; KNIJNIK, Jorge Dorfman. Motivos de adesão à prática de atividade física na vida adulta intermediária. Revista Mackenzie de Educação Física e Esporte, Rio de Janeiro, v. 5, n. 1, p. 23-34, 2006.

SEVERINO, Antonio Joaquim. Metodologia do trabalho científico. São Paulo: Cortez; 2007, $309 \mathrm{p}$.

SMIT, Barbara. Invasão De Campo: Adidas, Puma e os Bastidores do Esporte Moderno. $1^{\text {a }}$ ed. Rio de Janeiro, Editora Zahar; 2007, 287p.

TRIANI, Felipe. Esporte e Sociedade: da prática esportiva antiga à contemporânea. In.: TRIANI, Felipe; PIMENTEL, Paulo. Esporte, Educação Física e Sociedade. Rio de Janeiro, Autografia; 2016, 243p.

TRANCHITELLA, Marina. O Gerenciamento de Riscos em Eventos Esportivos: Um Estudo com Corridas de Rua. Revista Intercontinental de Gestão Desportiva, Niterói, v. 4, n. 1, p. 128-130, 2014. 2014.

TRUCCOLO, Adriana Barni; MADURO, Paula Andreatta; FEIJÓ, Eduardo Aguirre. Fatores Motivacionais de Adesão a Grupos de Corrida. Motriz, Rio Claro, v. 14, n. 2, p. 108-114, 2008.

TUBINO, Manoel José Gomes. O que é esporte. 3. ed. São Paulo: Brasiliense, 2006.

WEINBERG, Robert; GOULD, Daniel. Fundamentos da Psicologia do Esporte e do Exercício. $2^{\mathrm{a}}$. ed. Porto Alegre, Artmed; 2001, 706p.

ZIMERMAN, David; OSÓRIO, Luiz Carlos. Como Trabalhamos com Grupos. São Paulo, Livraria Duas Cidades; 1997, 289p.

\section{NOTAS DE AUTOR}

\section{AGRADECIMENTOS}

Os autores agradecem as pessoas que contribuíram com a realização do manuscrito.

\section{FINANCIAMENTO}

Não se aplica.

\section{CONSENTIMENTO DE USO DE IMAGEM}

Não se aplica. 


\section{APROVAÇÃO DE COMITÊ DE ÉTICA EM PESQUISA}

Teve aprovação do comitê de ética: CEP UERJ CAAE n: 76695517.0.0000.5259.

\section{CONFLITO DE INTERESSES}

Não há conflito de interesses.

\section{LICENÇA DE USO}

Os autores cedem à Motrivivência - ISSN 2175-8042 os direitos exclusivos de primeira publicação, com o trabalho simultaneamente licenciado sob a Licença Creative Commons Attribution Non-Comercial ShareAlike (CC BY-NC SA) 4.0 International. Estra licença permite que terceiros remixem, adaptem e criem a partir do trabalho publicado, desde que para fins não comerciais, atribuindo o devido crédito de autoria e publicação inicial neste periódico desde que adotem a mesma licença, compartilhar igual. Os autores têm autorização para assumir contratos adicionais separadamente, para distribuição não exclusiva da versão do trabalho publicada neste periódico (ex.: publicar em repositório institucional, em site pessoal, publicar uma tradução, ou como capítulo de livro), com reconhecimento de autoria e publicação inicial neste periódico, desde que para fins não comerciais e compartilhar com a mesma licença.

\section{PUBLISHER}

Universidade Federal de Santa Catarina. Programa de Pós-Graduação em Educação Física. LaboMídia - Laboratório e Observatório da Mídia Esportiva. Publicado no Portal de Periódicos UFSC. As ideias expressadas neste artigo são de responsabilidade de seus autores, não representando, necessariamente, a opinião dos editores ou da universidade.

\section{EDITORES}

Mauricio Roberto da Silva, Giovani De Lorenzi Pires, Rogério Santos Pereira.

\section{HISTÓRICO}

Recebido em: 28 de maio de 2018.

Aprovado em: 19 de dezembro de 2018. 